\title{
Luck egalitarianism without moral tyranny
}

\author{
Jesse Spafford $^{1}{ }^{\mathbb{D}}$
}

\begin{abstract}
Luck egalitarians contend that, while each person starts out with a claim to an equal quantity of advantage, she can forfeit this claim by making certain choices. The appeal of luck egalitarianism is that it seems to satisfy what this paper calls the moral tyranny constraint. According to this constraint, any acceptable theory of justice must preclude the possibility of an agent unilaterally, discretionarily, and foreseeably leaving others with less advantage under conditions of full compliance with the theory. This paper argues that claim forfeiture is built into luck egalitarianism specifically to preclude such moral tyranny. However, it contends that the dominant interpretation of luck egalitarianism fails to fully satisfy the moral tyranny constraint. It offers an alternative interpretation that both eliminates the possibility of moral tyranny and rescues the position from two other prominent objections that have been directed against luck egalitarianism.
\end{abstract}

Keywords Luck egalitarianism - Responsibility - Consequential responsibility · Moral tyranny

\section{The perils of holding people responsible}

A distinctive feature of luck egalitarianism is its incorporation of responsibility into an otherwise strictly egalitarian theory of distributive justice. Strict egalitarian theories are, by definition, insensitive to responsibility: they demand an equal distribution of advantage irrespective of anyone's past actions (where "advantage" refers to whatever currency of egalitarian justice one prefers). By contrast, luck egalitarians are willing to declare certain inequalities just if and only if those

Jesse Spafford

jesse.e.spafford@gmail.com

1 Trinity College, Dublin, Ireland 
inequalities correspond to some choice for which the worse off parties are responsible. For example, G. A. Cohen provides a representative statement of the luck egalitarian position when he asserts that "an unequal distribution whose inequality cannot be vindicated by some choice or fault or desert on the part of (some of) the relevant affected agents is unfair, and therefore, pro tanto, unjust" $(2009,7){ }^{1}$

As this statement indicates, a defining feature of luck egalitarianism is that it holds people responsible for making sanctionable choices, where a theory holds someone responsible for a choice just in case it maintains that she forfeits a claim to some quantity of advantage in virtue of that choice. ${ }^{2}$ This posited forfeiture of a claim is sometimes supplemented by the stronger corollary that not only is the agent not entitled to that advantage (e.g., to an equalizing transfer), but also she ought not receive that advantage. Many luck egalitarians, however, opt for the weaker, unamended version. ${ }^{3}$

A luck egalitarian theory that holds people responsible for sanctionable choices will have to answer two questions. First, which choices qualify as sanctionable? And, second, to what quantity of advantage does a person lose her claim when she makes a sanctionable choice? ${ }^{4}$ Most luck egalitarians answer these questions by either explicitly or tacitly assuming what might be called prudential contextualism: a person chooses sanctionably just in case she is responsible for leaving herself worse off than she could have been otherwise. ${ }^{5}$ She then forfeits a claim to however much advantage she could have had if she had chosen differently. For example, if the norm in a given society is that people who park on a certain street have their car

\footnotetext{
1 Other representative statements of luck egalitarianism include those made by Arneson (2011a, 243), Cohen (2006, 440; 2008, 17-18; 2011, 13), Lippert-Rasmussen (2015, 1), Temkin (1993, 13), and Vallentyne (2008, 58), among many others.

2 The notion of responsibility at issue here, then, is what has been alternately called "consequential responsibility" (Dworkin, 2000, 287; Stemplowska, 2009, 238; Knight and Stemplowska, 2011, 13), "substantive responsibility" (Scanlon, 1998, 248), and "holding people responsible" (Olsaretti 2009, 167-68). The idea is that the agent's relation to some misdeed (or morally good action) entails that she ought to be left worse off (or better off) than if she did not stand in that relation.

3 See, e.g., Segall $(2013,36)$.

4 This question is asking for what Serena Olsaretti calls a principle of stakes-i.e., "an account of what consequences can be justifiably attached to features that are the appropriate grounds of responsibility" $(2009,167)$. The first question then asks what these features are that function as such appropriate grounds. Olsaretti focuses only on the former question and brackets the latter; by contrast, this paper will suggest that the answers to the two questions are linked, as both the grounds of responsibility and their associated stakes follow from the same theoretical constraint, namely, what Sect. 2 calls the moral tyranny constraint.
}

5 The term "prudential contextualism" is a slight modification of Olsaretti's term "contextualism," which she uses to describe this dominant interpretation of luck egalitarian (2009, 180). The paper will not take a stand on the exact sense in which an agent must be responsible for leaving herself worse off-at least, beyond a few claims about the necessary conditions of such responsibility discussed below. It should be noted that not all luck egalitarians are prudential contextualists with some explicitly rejecting the position [e.g., Olsaretti (2009), Stemplowska (2009), and Thaysen and Albertsen (2017)]. These alternative views will be discussed below. It should also be noted that there is some dispute over whether certain influential luck egalitarians were contextualists. For a critical discussion, see Stemplowska (2013). 
towed, then the person who parks there and has her car towed forfeits her claim to the extra advantage she would have possessed had her car not been towed.

Unfortunately, this interpretation of luck egalitarianism leaves the position vulnerable to a number of serious objections. First, there is Richard Arneson's objection that luck egalitarianism delivers incorrect results in cases of charitable action. For example, a Mother Teresa figure who impoverishes herself assisting the poor would, on the prudential contextualist view, have made a sanctionable choice, as she leaves herself worse off in a way that could have been avoided. Thus, the luck egalitarian who endorses prudential contextualism would seemingly be committed to saying that she is not entitled to any sort of compensatory redistribution; however, Arneson contends that this is the wrong result, with luck egalitarianism then being rejected as part of a modus tollens argument (Arneson, 2011a, 244; 2011b, 33-34). ${ }^{6}$

Second, there is what Susan Hurley has called luck egalitarianism's "boring problem," which calls into question the core luck egalitarian claim that sanctionable choice can justify inequality. Hurley argues that this claim is plausible only if sanctionable choosers are responsible for the inequality in question. However, on the prudential contextualist view, a person chooses sanctionably iff she is responsible for her particular level of advantage. Given that someone can be responsible for her level of advantage but not the associated inequality - as the inequality is partly a function of the advantage levels of others for which they are responsible-it follows that sanctionable choice cannot justify inequality in the way that luck egalitarians claim (Hurley, 2003, 160-161). ${ }^{7}$

Finally-and most importantly for the purposes of this paper-there is Serena Olsaretti's moral tyranny objection. Note that, on the prudential contextualist view, a person's claim to advantage will often depend on the capricious choices of others in a way that seems unacceptable (Olsaretti, 2009, 176). If, for example, no one bothered to tow the driver's car, then her decision to park would not be a sanctionable choice, and she would not forfeit any claim to advantage. By contrast, someone choosing to tow her car would strip her of her claim to some share of advantage. Further, the choice to tow/not tow will determine how justice-compliant people treat the car driver. If the car is not towed but someone later steals it out of her garage, compliant people would be compelled to make transfers to the driver to compensate her for the loss of her vehicle (as she still has a claim to as much advantage as everyone else). By contrast, if the car is towed, compliant people would not make any such transfers. Thus, a luck egalitarian theory interpreted in a prudential contextualist fashion would seem to sanction an unacceptable form of

\footnotetext{
${ }^{6}$ An alternative version of this argument is presented by Larry Temkin who presents the case of a good Samaritan who rescues a drowning child from a pond but injures herself in the process $(2011,63)$. Here, again, it is maintained that her failure to act prudently means she is responsible for this personal cost and is to be denied compensation as a penalty.

7 For a recent paper that attempts to extend the boring problem into a more general objection to theories that declare luck-based inequality unjust, see Jeffers (2020).
} 
moral tyranny-i.e., it grants individuals the undue power determine how others are treated by morally-compliant people. ${ }^{8}$

This paper will present an alternative account of sanctionable choice that avoids all three of these objections. Specifically, it will propose that an agent chooses sanctionably just in case the choice, under conditions of full compliance, can reasonably be expected to produce less appropriately distributed advantage than some alternative choice that could have been made. Much of the paper will be concerned with explaining what is meant by each of these terms and how the proposed account resolves the three objections. First, though, the paper will present the moral tyranny objection in greater detail and explain why it poses such a problem for luck egalitarianism. This explication is the subject of Sect. 2, which contends that the reason for incorporating a responsibility component into an otherwise strictly egalitarian theory is to preclude the possibility of moral tyranny. Given that this is the motivation for adopting luck egalitarianism, it is a serious problem if the theory simply replaces one form of moral tyranny with another. The remaining sections of the paper attempt to provide an alternative interpretation of luck egalitarianism that avoids countenancing any such tyranny (and, additionally, resolves the other two objections presented above).

\section{Contextualism and moral tyranny}

To see why a concern with moral tyranny motivates the luck egalitarian incorporation of responsibility, it is helpful to examine a certain species of reductio argument that plagues strict egalitarian theories that are, by definition, insensitive to responsibility (i.e., theories that demand equality regardless of past actions). Consider how a principle that demands strict equality of advantage would handle the case of a spiteful person who maliciously destroys any advantage she receives. In this case, a strict egalitarian would demand that advantage continually be reallocated to this person such that her share remains as great as everyone else's - a demand that is sustained even as she destroys each bit of advantage transferred to her until, eventually, no one has any advantage left to transfer. This result is an apparent reductio of strict egalitarianism.

Other examples popularly cited by luck egalitarians can be substituted into the reductio to reach the same conclusion. For example, consider G. A. Cohen's Aesopian case of the ant who assiduously works all summer storing up food while a neighboring grasshopper lounges idly-a decision the grasshopper makes even while recognizing that she will end up worse off when winter comes (2008, 27-8). In this case, a strict egalitarian principle of justice would demand that the ant redistribute some of her food to the grasshopper; however, there is something seemingly unfair about the ant having to make do with less because of the grasshopper's choice not to work. Thus, insofar as justice is supposed to track

\footnotetext{
${ }^{8}$ Note that this is a slight extension of Olsaretti's argument, which is more narrowly focused on claims to advantage.
} 
fairness, a strict egalitarian principle must be rejected, as it declares an unfair outcome just. $^{9}$

The judgement that redistribution in these cases would be unfair points to a general theoretical concern motivating the rejection of strict egalitarianism in favor of luck egalitarianism. Cohen has suggested that such redistribution would be unfair because it is a form of exploitation, where exploitation runs contrary to egalitarianism (Cohen, 2011, 8). However, as Michael Otsuka notes, it is unclear in what respect such exploitation can be inegalitarian given that the redistribution is equalizing by definition (Otsuka, 2010, 223). Rather, Otsuka plausibly argues that what is unfair about such redistribution is that it forces some people to "pick up the tab" for the poor choices of others $(2010,229)$.

To put this point more precisely, what is seemingly unfair about strict egalitarianism is that it allows one person to unilaterally, discretionarily, and foreseeably act in a way that, under conditions of full compliance with the theory in question, leaves others with less advantage than they would have had otherwise. These italicized terms each require explication. Beginning with the notion of full compliance, note that the spiteful destroyer may not, as a matter of fact, leave others with less, as they might refuse to transfer any of their advantage to her. Rather, what she does is strip others of a claim to advantage according to the strict egalitarian theory - while simultaneously acquiring a claim to that stripped advantage-such that others would make transfer to her if they were to comply with the theory. In other words, strict egalitarianism gives her the power to leave fully-compliant people with less, and it is for this reason that it seems unacceptable.

A person unilaterally leaves another with less advantage under conditions of full compliance-or, to introduce a bit of simplifying terminology, leaves another with less $_{\mathrm{FC}}$ - just in case the latter is unable to avoid the loss of advantage. For example, when either the spiteful person destroys advantage or the grasshopper declines to collect food, there is nothing the other parties can do to insulate themselves from losing a claim to some of their advantage and, thus, ending up with less $\mathrm{FC}_{\mathrm{FC}}$. By contrast, if these parties could take some action that would negate their claim loss (without foregoing any advantage), strict egalitarianism would seem less theoretically problematic.

The proposition that a person discretionarily leaves others with less advantage asserts two things. First, it asserts that there was an alternative choice that the agent could have made that would not have resulted in the person ending up with less $\mathrm{FC}_{\mathrm{FC}}$. Second, this alternative choice has to be not merely modally available in the justmentioned sense, but it also has to be morally available in the sense that the agent has no duty of justice to refrain from making that choice. For example, suppose that a doctor could significantly improve a patient's life by performing an invasive medical procedure to which the patient has not consented. If the doctor chooses not

\footnotetext{
${ }^{9}$ For similar motivating cases, see Kymlicka $(2002,73)$ and Stemplowska $(2009,241,252-3)$. Note that such cases seem to count against Shlomi Segall's (2016) thesis that there is nothing morally objectionable about any equal state of affairs. Contra Segall, the luck egalitarian theory posited by this paper will entail that equal distributions generated by sanctionable choice are unjust. Any theory that does not have this implication will problematically allow for what the paper below calls "moral tyranny."
} 
to perform the procedure, she will leave the patient with less $\mathrm{FC}_{\mathrm{FC}}$ advantage than if the procedure were performed. However, there is seemingly nothing problematic about a theory of justice that countenances this result, as the doctor is simply doing what she has to do when she chooses not to carry out the procedure (in the normative sense of "has"). Thus, a theory only seems unacceptable when it entitles people act in non-obligatory, advantage-diminishing ways-e.g., as strict egalitarianism does in the grasshopper and spiteful destroyer cases.

Finally, a theory of justice only seems unacceptable if it countenances people foreseeably leaving others with less $\mathrm{FC}_{\mathrm{FC}}$. For example, suppose that the grasshopper collected just as much food over the summer as the ant, but stored it in a location that was destroyed by an unforeseeable wildfire. In this case, both strict and luck egalitarian theories would require a fully-compliant ant to transfer some of her food that she would have been permitted to keep had the grasshopper chosen a different storage location. And, in contrast to strict egalitarianism's prescription in the original case, this result seems unproblematic, with the lack of foreseeability explaining these different intuitions.

Together, these four concepts help articulate the individually necessary and jointly sufficient conditions of a theory granting agents an unacceptable sort of moral tyranny over others. When a theory of justice entails that one person can unilaterally, discretionarily, and foreseeably act in a way that leaves others with less $_{\mathrm{FC}}$, it transforms people into moral tyrants who can willfully dictate that others must transfer away advantage if they are to remain in compliance with the demands of justice. The motivating premise of luck egalitarianism-with its correlative rejection of strict egalitarianism - is that any acceptable theory of justice must rule out such moral tyranny (at least insofar as it is possible to rule out such tyranny). ${ }^{10}$ Call this the moral tyranny constraint. ${ }^{11}$

The advantage of luck egalitarianism is that it satisfies this theoretical constraint via its incorporation of responsibility. For example, in the spite case, the agent is held responsible for destroying her own advantage, thereby making the resulting inequality just, which, in turn, entails that full-compliers will not end up with less in virtue of the spiteful agent's choices. Similarly, luck egalitarianism holds the grasshopper responsible for her failure to work, thereby preventing a fullycompliant ant from having to "pick up the tab" for the grasshopper's bad choice.

\footnotetext{
10 This parenthetical is included because there are certain choices an agent might make that will necessarily reduce another's share under full compliance, irrespective of what theory is the correct one. If, for example, the spiteful person destroyed the entire planet, she would lessen the advantage of others given full compliance with any theory of justice. Thus, it is no strike against a theory that it allows for moral tyranny in this instance. Only if a theory countenances avoidable moral tyranny does it violate the moral tyranny constraint.

11 This constraint would similarly condemn a theory that assigned no control rights over objects or resources and, thus, allowed people to snatch whatever resources they wanted away from other people. Such a theory would not maintain that any rectification must be paid if advantage is stripped away from a person via resource confiscation. Thus, if one person strips advantage away from another in this way, fullcompliers will not make any rectification, thereby leaving the affected party with less $\mathrm{FC}_{\mathrm{F}}$. The apparent tyranny of a theory that has this consequence provides additional support for the posited formulation of the moral tyranny constraint (because the account properly declares this theory tyrannical).
} 
Thus, unlike strict egalitarianism, luck egalitarianism seems to satisfy the moral tyranny constraint, with this theoretical advantage explaining why it is the favored position of contemporary egalitarians.

However, if the moral tyranny constraint is the reason for accepting luck egalitarianism, then it is a significant problem if the theory is interpreted in a way that violates that constraint. As noted above, Olsaretti observes that most luck egalitarians tacitly assume a contextualist theory of sanctionable choice wherein it is maintained that a person forfeits a claim to however much advantage she foregoes due to contingent social circumstances and the choices that others make $(2009,180)$. Olsaretti illustrates this theory with Marc Fleurbaey's (1995) case of a reckless motorcyclist who crashes and is injured as a result of driving too fast and not wearing a helmet. She notes that, on the contextualist theory, the quantity of advantage to which the motorcyclist forfeits a claim will problematically depend upon whether a passerby provides assistance, leaves her unaided, or confiscates her motorcycle (2009, 175-6). Given that the behavior of full-compliers is determined by what claims people possess, it follows that the motorcyclist would be left with less $_{\mathrm{FC}}$ if her motorcycle is confiscated than if no such confiscation occurs. Thus, contextualist luck egalitarianism will violate the moral tyranny constraint, as it enables the passerby to unilaterally, discretionarily, and foreseeably leave the motorcyclist with less advantage than she might have had otherwise. This is a particularly problematic result given that satisfying this constraint was the motivating reason for adopting luck egalitarianism in the first place.

\section{Moralized contextualism}

What is needed is an alternative account of sanctionable choice that satisfies the moral tyranny constraint. The task of the remainder of the paper is to provide just such an account. First, though, it is worth briefly considering an alternative account that might seem like an easy fix for contextualism's moral tyranny problem. This account maintains that a person chooses sanctionably just in case (a) she leaves herself worse off than she would have been otherwise, (b) she could have reasonably expected this outcome given her particular social circumstances, and (c) she does not end up worse off as a result of someone infringing upon her rights. She then forfeits a claim to the surplus advantage she could have had if she had chosen differently. ${ }^{12}$

\footnotetext{
12 This seems to be what Olsaretti is suggesting when she says that "the notion of responsibility a theory of justice employs is necessarily moralized, in that it must presuppose a view of what individuals owe to one another in order to determine the legitimate consequences of choices" $(2009,186)$. A more formal articulation of moralized contextualism is proposed by Zofia Stemplowska (2009), though she significantly qualifies the view. Regrettably, working through the interesting details of her view would take things too far afield.
} 
This moralized contextualism seems to rule out some of the more intuitively problematic forms of moral tyranny endorsed by standard contextualist accounts. For example, in the motorcycle case, one might think that the passerby who confiscates the motorcycle infringes upon the property rights of the motorcyclist. Thus, condition (c) is not met, which entails that the motorcyclist is not guilty of sanctionable choice and does not forfeit a claim to the advantage that comes from the continued use of her motorcycle. Further, given that she still has a claim to this advantage, full-compliers will ensure that she retains possession of this advantage (e.g., by returning the motorcycle), thereby precluding the possibility of the passerby choosing to leave her with less $_{\mathrm{FC}}-\mathrm{a}$ result that suggests that moralized contextualism satisfies the moral tyranny constraint.

However, there are two problems with this suggestion. First, even if moralization limits the extent to which a person is able to leave others with less $\mathrm{FC}_{\mathrm{FC}}$, it does not eliminate her ability to leave others with less $\mathrm{FC}_{\mathrm{FC}}$. For example, while the motorcyclist may have a right to her motorcycle, she does not obviously have a right to assistance after the accident (at least, if assisting would be reasonably costly to the passerby). Given the absence of this right, moralized contextualism delivers the same result as standard contextualism in the case where the passerby chooses not to assist the motorcyclist: the motorcyclist forfeits a claim to however much advantage she loses as a result of the passerby's choice. Thus, full compliance with moralized contextualist luck egalitarianism would not require that any compensatory transfers be made to the motorcyclist, which, in turn, implies that the passerby can leave the motorcyclist with less $\mathrm{FC}_{\mathrm{FC}}$. The fact that moralized contextualism grants the passerby this ability entails that the theory still violates the moral tyranny constraint.

The second problem with the moralized contextualist approach is that it presupposes that which it is supposed to demonstrate. Note that a luck egalitarian theory of justice is supposed to answer the question of what rights people have over objects and resources. Indeed, this is the very point at issue in debates over taxes and transfers, with luck egalitarianism contending that these resources should be distributed in a responsibility-sensitive egalitarian fashion. However, one cannot then assume that there is a given set of rights over objects for a luck egalitarian theory to use as an input. For example, it cannot be maintained that the passerby infringes upon the motorcyclist's right to use her motorcycle, as it is an open question whether the motorcyclist does, in fact, have a right to use that motorcycle (particularly given her choice to ride without a helmet). Thus, a luck egalitarian theory that assumes moralized contextualism not only fails to meet the moral tyranny constraint, but also appears unacceptably circular.

\section{A theory of sanctionable choice}

Given the unacceptability of (moralized) contextualism, luck egalitarians need a theory of sanctionable choice that satisfies the moral tyranny constraint. This section proposes the following account: an agent chooses sanctionably just in case she fails to maximize warranted expected distributed advantage assuming full compliance. 
The task of this section is to explicate each of these italicized concepts and explain why the theory defines sanctionable choice in these terms.

To begin, recall that a theory satisfies the moral tyranny constraint iff it does not enable any person to leave others with less $\mathrm{FC}_{\mathrm{FC}}$. There are two ways that a theory might enable a person in this way. First, it might grant her the power to directly strip someone of a claim to advantage (and reassign that claim to someone else), thereby changing the percentage of available advantage assigned to each person. Second, and more importantly for these purposes, it might fail to adequately sanction those whose actions would diminish the total quantity of available advantage if all persons were to fully comply with the theory-or, to introduce a bit more shorthand, those who diminsh FC $_{\mathrm{FC}}$ (or reduce $\mathrm{FC}_{\mathrm{FC}}$ ) the total quantity of advantage. To put this point a bit more precisely, such a failure occurs when a person reduces ${ }_{\mathrm{FC}}$ the total quantity of advantage by some quantity $x$ but the theory in question holds that her just share is diminished by a quantity that is less than $x$. This is what a strict egalitarian theory asserts in the case of the spiteful destroyer: even as the destroyer reduces ${ }_{\mathrm{FC}}$ the total advantage available by quantity $x$, the theory holds that she only forfeits a claim to a quantity of $x / n$, where $n$ is the number of people in the scenario. As a result, if others were to respect her claim, at least some would end up with less advantage than they would have had otherwise.

To avoid moral tyranny, then, a theory must hold that those who reduce $\mathrm{FC}_{\mathrm{F}}$ the total quantity of advantage forfeit a sufficient quantity of advantage such that others will not end up worse off after the transfers demanded by justice have been made. In other words, when people reduce ${ }_{\mathrm{FC}}$ the total quantity of advantage, the theory must declare that they choose sanctionably and hold them responsible by reducing the quantity of advantage to which they are entitled. This is the core idea of the theory of sanctionable choice presented above. However, some additional groundwork and a few refinements are needed to both make the theory acceptably egalitarian and ensure that the correct people are held responsible.

To further explicate the theory, it will be helpful to stake out a position regarding the equilisandum of luck egalitarian justice. Specifically, it will be assumed that what is to be equalized is not the advantage persons possess at a particular time or over some specified period, but, rather, their lifetime level of advantage. Thus, there is no injustice in an arrangement where one person labors for the first half of her life while another relaxes, so long as the two switch roles for the second halves of their respective lives. Early on, the two people will have very different quantities of advantage; however, injustice only obtains if things are not adequately evened out in the future. ${ }^{13}$ Given this assumption, any future use of terms like "the distribution of advantage" should be understood as referring to how lifetime advantage is distributed.

\footnotetext{
13 This assumption helps to simplify things in the following way. Below, there will be much talk of how advantage is distributed. If the equilisandum of the luck egalitarian principle is lifetime advantage, then there is only one distribution to be assessed, namely, the lifetime levels of advantage everyone ends up with. By contrast, alternative approaches entail that there are many distributions that obtain across time, each of which would have to be assessed. That said, there are objections to taking entire lives as the basic unit of egalitarianism. See, for example, McKerlie (1989) and Temkin (1993).
} 
With this simplifying assumption in place, it becomes possible to quantify the advantage that an agent destroys $\mathrm{sC}_{\mathrm{FC}}$ with any given choice. A natural temptation is to simply calculate the total quantity of advantage destroyed $\mathrm{FC}_{\mathrm{FC}}$ by her choice by comparing how much total advantage obtains given her choice to the maximum quantity that would have obtained had she chosen differently (assuming full compliance in both cases). However, this approach is unacceptable for two reasons. First, it would still violate the moral tyranny constraint. Note that a consequence of using this method is that later choices will sometimes determine whether advantage was destroyed $\mathrm{FC}_{\mathrm{FC}}$ by an earlier choice. Thus, a theory that calculates lost advantage in this way grants later choosers the power to unilaterally, discretionarily, and foreseeably render an earlier choice sanctionable and thereby leave the earlier chooser with less $_{\mathrm{FC}}$. Second, this approach would make sanctionable choice a function of luck, as a choice might reduce $_{\mathrm{FC}}$ the quantity of total advantage more than a rival choice due to an unforeseeable future event. Given that sanctionable choice requires that the agent be responsible for the state of affairs that grounds her loss of a claim to advantage - and the fact that agents are not responsible for the unforeseeable consequences of their actions-it follows that the sanctionability of a choice cannot be a function of whether or not it reduced $_{\mathrm{FC}}$ the total quantity of advantage relative to a counterfactual choice.

The observation that responsibility requires foreseeability suggests an alternative approach to quantifying how much advantage is destroyed $\mathrm{FC}_{\mathrm{FC}}$ by a choice: instead of determining whether a choice reduces $\mathrm{FC}_{\mathrm{FC}}$ the total quantity of available advantage, one must determine whether that choice is expected to reduce $\mathrm{FC}_{\mathrm{FC}}$ the total quantity of advantage. Note that, at any point in time, there is a set of possible ultimate distributions of advantage that could still arise given all preceding events (where distributions extend across lifetimes as described above). Further, for any given choice that an agent might make, each of those distributions will have a particular probability of obtaining conditional on that choice being made and all persons complying with the demands of justice. These conditional probabilities make it possible to calculate the expected advantage of that choice (assuming full compliance) by taking the total quantity of advantage of each distribution, multiplying it by the aforementioned conditional probability, and summing the results. This value can then be compared to the expected advantage value of other rival choices that could have been made. When a person makes a choice that has a lower expected advantage value than a rival choice that she could have made, she can be preliminarily understood as having chosen sanctionably, as her action is expected to diminish ${ }_{\mathrm{FC}}$ the total quantity of advantage. ${ }^{14}$

This account of sanctionable choice is merely preliminary because a significant revision must be made to how the expected value of a choice is calculated. To calculate the expected value of a choice, one must assign an advantage value to each of the possible distributions and then multiply that value by the probability of that distribution obtaining conditional on the choice being made and future full

\footnotetext{
14 This use of expected value has been embraced by a number of luck egalitarians including Arneson (1989), Knight (2013), and Vallentyne (2002, 2008).
} 
compliance with the demands of justice. So far, this advantage value has been set equal to the total quantity of advantage that obtains in that distribution (as bringing about a distribution with less total advantage leaves others with less $\mathrm{FC}_{\mathrm{FC}}$, ceteris paribus). However, using total advantage obscures how advantage is distributed across persons. This is a problem because the moral tyranny constraint requires that a choice leaves no person with less $_{\mathrm{FC}}$ than they would have had, not people on

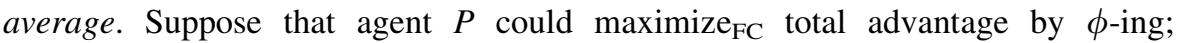
however, such maximization leaves person $Q$ with nothing and does not allow for any transfers to be made to her despite $Q$ having a claim to a share of the total advantage. Alternatively, $P$ might $\psi$ and bring about a distribution with a modest quantity of total advantage but where all persons' claims to advantage are respected. In this case, $P \phi$-ing would leave $Q$ with less $_{\mathrm{FC}}$ than if $P \psi$-ed, as full-compliers would not be able to transfer advantage to $Q$. Given this result, a theory of sanctionable choice must declare $\phi$-ing to be sanctionable if it is to satisfy the moral tyranny constraint. Thus, an acceptable theory cannot hold that a person chooses sanctionably if and only if she fails to maximize $\mathrm{FC}_{\mathrm{FC}}$ expected total advantage. ${ }^{15}$

This observation demands that the theory be refined as follows: a sanctionable choice does not merely fail to maximize the expected total advantage under conditions of full compliance but, rather, fails to maximize the total quantity of appropriately distributed advantage under conditions of full compliance. The idea here is as follows. At any given point in time, a luck egalitarian theory of justice will dictate what ratios of possessed advantage are just: each person is entitled to as much advantage as everyone else minus however much advantage she has forfeited due to previous sanctionable choices. When these ratios all obtain, advantage can be said to be appropriately distributed, with fully compliant people being those who do everything they can to realize those ratios. The problem noted immediately above is that certain choices preclude the possibility of fully compliant people distributing advantage appropriately, thereby leaving some people with less $\mathrm{FC}_{\mathrm{FC}}$ than they could have had otherwise. To avoid this form of moral tyranny, the theory must treat such choices as sanctionable in addition to choices that leave others with less $_{\mathrm{FC}}$ by reducing $_{\mathrm{FC}}$ the total quantity of transferrable advantage.

This constraint can be satisfied by modifying the advantage values used to calculate the expected advantage of a choice. Specifically any distribution where advantage is appropriately distributed receives an advantage value equal to the total quantity of advantage (i.e., the sum of each person's lifetime advantage). By contrast, for any distribution $U$ where advantage is inappropriately distributed, its advantage value is calculated via the following procedure. First, of those distributions that have a non-zero probability conditional on all past events

\footnotetext{
15 It is worth noting that $P \psi$-ing will also leave others with less $\mathrm{FC}_{\mathrm{F}}$ than they would have had if she $\phi$-ed. Thus, one might worry that moral tyranny is inevitable in cases where advantage is non-transferrable. However, this concern can be sidestepped by qualifying the moral tyranny constraint such that moral tyranny does not obtain if the person who is left with less $_{\mathrm{FC}}$ is only left worse off relative to a counterfactual where she would have had more ${ }_{\mathrm{FC}}$ advantage than she had a claim to. Indeed, there is seemingly nothing problematic about a theory that enables agents to deny full compliers advantage exceeding that to which they have a claim. For the sake of parsimony, though, this rest of the paper will gloss over this qualification.
} 
obtaining, identify the distribution $E$ that has the greatest total appropriately distributed advantage. Second, identify all those persons in $U$ who have less advantage than they would have had in $E$. Third, sum the differences between how much advantage each such person has in $E$ and how much she has in $U$. Fourth, calculate the advantage value of $U$ by subtracting this sum from the total value of $E$ (as this reduction reflects how much less $_{\mathrm{FC}}$ advantage people end up with in $U$ relative to the counterfactual $E$ where their just shares are maximized). Fifth, weight the advantage value of each distribution by multiplying it by the probability that the distribution obtains conditional on the choice in question being made and all persons complying with the demands of justice going forward. ${ }^{16}$ Finally, calculate the expected distributed advantage value of the choice by summing those weighted advantage values.

Once the expected distributed advantage values of each possible choice have been calculated, it becomes possible to compare the value of the actual choice to those of rival choices that could have been made. When the former is less than one of latter values, the agent is responsible for leaving other people with less $_{\mathrm{FC}}$. Further, this difference quantifies the extent to which the agent is responsible for leaving others with less $_{\mathrm{FC}}$. Thus, to satisfy the moral tyranny constraint, luck egalitarians can maintain that failing to maximize expected distributed advantage is the necessary and sufficient condition of sanctionable choice, with the agent forfeiting a quantity of advantage equal to (the absolute value of) the difference between the expected distributed advantage value of her choice and the value of the choice with the maximal expected distributed advantage value. Additionally, luck egalitarians must maintain that those whose advantage would have been diminished $_{\mathrm{FC}}$ absent such forfeiture also gain a claim to a quantity of the forfeited advantage-specifically, a quantity equal to the amount that they would otherwise have lost had the sanctionable agent preserved her claim. ${ }^{17}$ The joint effect of this forfeiture and correlative claim acquisition is that full compliers will now redirect the forfeited advantage to those who would have been left worse off in the absence of such forfeiture. Thus, the proposed theory of sanctionable choice precludes the agent from leaving others with less $_{\mathrm{FC}}$ and thereby satisfies the moral tyranny constraint.

One final bit of elaboration is needed to complete the formal account of sanctionable choice. So far, sanctionable choice has been defined in terms of expected distributed advantage-where this value is a function of distributions' distributed advantage values and the conditional probabilities of those distributions obtaining. However, note that the term "probability" is ambiguous. On the one

\footnotetext{
16 Note that to avoid circularity, the theory must maintain that, when determining what fully-compliant people will do given some choice, it must be assumed that they will treat the choice as non-sanctionable. Otherwise the theory will problematically maintain that the sanctionability of a choice depends on what fully compliant people will do in response to that choice, which, in turn, depends on whether the choice is sanctionable. This stipulation is perhaps a bit ad hoc, but this slight theoretical vice does not seem like a significant problem given the account's many significant theoretical virtues.

${ }^{17}$ For the sake of concision, the paper will only talk of the sanctionable party forfeiting a claim going forward. However, this should always be taken as shorthand for the assertion that the sanctionable party forfeits a claim and the relevant non-sanctionable parties acquire claims in the way just described.
} 
hand, it might refer to objective probabilities, which, in this case, represent how likely it is in some metaphysical sense that a distribution will arise. Alternatively, it might refer to subjective probabilities representing the agent's beliefs about how probable it is that a distribution will arise. To eliminate this ambiguity, one can adopt Carl Knight's suggestion that the proper account of probability to incorporate into luck egalitarian calculations of expected value is warranted subjective probability adjusted for non-culpable incapacity (2013, 1067). Briefly, Knight contends that the relevant probability is that which the agent should have assigned given the evidence available to her-at least, in those cases where she is capable of assessing that evidence (1067). The advantage of this evidentialist view is that it does not differentially hold people responsible for their unchosen epistemic states. By contrast, on the objective probabilities approach, people might be unaware of relevant objective probabilities "through no fault or choice of their own," and this makes it unfair to hold them responsible for non-maximizing choices (1066). Similarly, using subjective probabilities is unfair because those who are, as a matter of luck, overly confident that their choices are optimal will be found less culpable than those who lack that confidence (1066).

For the purposes of this paper, it is helpful to restate Knight's argument in terms of responsibility. An agent cannot seemingly be responsible for what she could not know given the evidence available to her. Further, even if she could know certain things, she may not be responsible for failing to form the proper beliefs given certain extenuating circumstances. ${ }^{18}$ Given that responsibility is a necessary condition of sanctionable choice, it follows that an account of sanctionable choice that incorporates calculations of expected value should adopt Knight's notion of probability. ${ }^{19}$ Thus, sanctionable choice should be understood as a failure to maximize warranted expected distributed advantage (WEDA) under conditions of full compliance. ${ }^{20}$

\footnotetext{
18 For more on this point, see Vallentyne (2002, 536).

19 One might slightly amend Knight's account in the following way. Knight suggests that, in cases where an agent is not culpable for her failure to assess the evidence, she should be treated as having not made a choice at all, and, thus, not acted culpably $(2013,1068)$. However, one might alternatively think that, in cases where an agent is not responsible for her incorrect beliefs about how likely various distributions are to obtain, she might still be responsible for making a sub-optimal choice given those beliefs. Thus, one might calculate expected distributed value using subjective probabilities in such cases.

${ }^{20}$ One consequence of incorporating Knight's suggestion is that the proposed theory of sanctionable choice does not countenance option luck. Briefly, option luck is generally understood to be the outcome that results from deliberate and avoidable gambles, with many luck egalitarian theories taking persons to have chosen sanctionably if (a) they choose to make such a gamble and (b) they lose out on advantage as a result (see, e.g., Dworkin 1981, 293). In other words, if a person gambles and loses, this is judged to be bad option luck for which the person is held responsible (i.e., the fact that she ends up worse off than others is held to be just by the theory). By contrast, the proposed theory does not hold people responsible for losing a gamble; rather, it holds them responsible for making any gamble that does not maximize WEDA, irrespective of how that gamble turns out. It is, thus, a variety of what Shlomi Segall has called "all-luck egalitarianism" (2010, 46).
} 


\section{Applying the theory}

This abstract description of the theory can be illustrated by applying it to a highlysimplified version of Fleurbaey's (1995) reckless motorcyclist case. Specifically, it will help to provide some invented numbers to demonstrate how the relevant calculations are carried out, beginning with the WEDA value of the motorcyclist choosing to wear a helmet (Table 1):

Each column of the table represents a distribution, where that distribution is defined in terms of the unique set of events compatible with the ultimate quantity of advantage possessed by all persons (in this case, the motorcyclist and the passerby). In Distribution 1, the motorcyclist wears her helmet, does not crash, and no subsequent transfers of advantage (or additional events) occur. In Distribution 2, the motorcyclist wears a helmet, crashes, and is then assisted by a passerby. Distribution 3 is defined by the same series of events as Distribution 2, only the passerby also makes an equalizing transfer to the motorcyclist. And, finally, in Distribution 4, the passerby simply drives past the injured motorcyclist and does not assist her (perhaps because the passerby simply does not notice her predicament). ${ }^{21}$

The first row of the table represents how much advantage each person is stipulated to possess in each distribution. In Distribution 1, where the motorcyclist does not crash, she and the passerby each end up with 500 units of advantage. In Distribution 2, the passerby is able to costlessly treat the motorcyclist's injuries from the crash and, thus, is left with the same quantity of advantage that she would have had if no crash had occurred (500 units). The motorcyclist, however, is a bit bruised and battered, so ends up with only 480 units of advantage. In Distribution 3, the passerby's supplemental transfer increases the motorcyclist's advantage to 490 , but that comes at the expense of the passerby, who also ends up with 490 units of advantage. Finally, if no assistance is given, the passerby maintains her original 500 units of advantage while the motorcyclist's untreated injuries reduce her advantage to 360 units.

The second row of the table represents the advantage value of each of the four distributions, where this value is a function of the values listed in the first row. As noted above, the first step of calculating the advantage value of a distribution is to identify the distribution with the greatest total quantity of advantage that is appropriately distributed and that has a non-zero probability of obtaining conditional on the choice under consideration being made under conditions of full compliance. Assuming no prior sanctionable choice on the part of either party, Distribution 1 satisfies these conditions, and, thus, receives advantage value equal to the total advantage possessed by all persons (1000 units). The next step is to calculate the advantage value of each additional distribution by identifying all of the people in that distribution who end up worse off than they would have in the comparison distribution. In Distributions 2 and 4, only the motorcyclist ends up worse off while, in Distribution 3, both the motorcyclist and the passerby end up

\footnotetext{
${ }^{21}$ For these purposes, it will be assumed that the passerby is unable to make any transfer to the motorcyclist in this scenario, perhaps because she continues traveling to a distant location where her spatiotemporal position makes it impossible to re-locate the motorcyclist and transfer advantage to her.
} 
Table 1 Calculating the WEDA Value of Motorcycling with a Helmet

\begin{tabular}{llllc}
\hline & $\begin{array}{l}\text { Distribution 1 } \\
\text { Wears a Helmet }\end{array}$ & Distribution 2 & Distribution 3 & Distribution 4 \\
\cline { 2 - 5 } & Does Not Crash & Crashes & & \\
\cline { 2 - 5 } & No Transfer & $\begin{array}{l}\text { Assist (No } \\
\text { Transfer) }\end{array}$ & Assist (Transfer) & Failure to Assist \\
& & $\mathrm{M}=480, \mathrm{P}=500$ & $\mathrm{M}=490$, & $\mathrm{M}=360$, \\
Distributed Advantage & $\mathrm{M}=500$, & $\mathrm{P}=490$ & $\mathrm{P}=500$ \\
Advantage Value & 1000 & 980 & 980 & 860 \\
$\begin{array}{l}P \text { (Distribution I } \\
\text { Helmet) }\end{array}$ & 0.7 & 0 & 0.1 & 0.2 \\
Expected Advantage & 700 & 0 & 98 & 172 \\
WEDA & 970 & & & \\
\hline
\end{tabular}

worse off. Each difference in advantage is then subtracted from the advantage value of the comparison distribution. So, for Distribution 3, one would subtract 10 (the difference between how much advantage the motorcyclist has in Distribution 1 and how much she has in Distribution 3) and another 10 (the difference between how much advantage the passerby has in Distribution 1 and how much she has in Distribution 3) from 1000 to get an advantage value of 980 .

The third row of the table represents the warranted probability of each distribution obtaining conditional upon the motorcyclist not wearing a helmet under conditions of full compliance. For the purposes of this example, it is stipulated that the motorcyclist's evidence suggests there is a probability of 0.7 that Distribution 1 obtains, a probability of 0 that Distribution 2 obtains, a probability of 0.1 that Distribution 3 obtains, and a probability of 0.2 that Distribution 4 obtains. Distribution 2 has a probability of 0 because the theory is only concerned with the probability of a distribution obtaining under conditions of full compliance. Given that full compliance requires equalizing holdings (as neither party has chosen sanctionably prior to the motorcyclist's choice), a fully-compliant passerby will make equalizing transfers insofar as she has the ability to do so. Thus, Distribution 2 is assigned a probability of 0 , and whatever probability it would have been assigned assuming actual compliance (say, 0.1 ) is added to the probability of Distribution 3 obtaining under actual compliance (again, 0.1) to yield the probability of Distribution 3 obtaining under conditions of full compliance (0.2).

The fourth row lists the expected distributed advantage value of each distribution. The values in this row are determined by multiplying the advantage value of each distribution by its conditional probability. For example, Distribution 3 has an advantage value of 980 , which is then multiplied by the conditional probability of 0.1 to get an expected distributed advantage value of 98 . The WEDA value for the choice not to wear a helmet is the sum of the distributed advantage values of all possible distributions, which, in this case, equals 970 (Table 1). 
Table 2 Calculating the WEDA Value of Motorcycling without Wearing a Helmet

\begin{tabular}{|c|c|c|c|c|}
\hline & \multicolumn{4}{|c|}{ Does Not Wear a Helmet } \\
\hline & \multirow{2}{*}{$\begin{array}{l}\text { Does Not Crash } \\
\text { Transfer }\end{array}$} & \multicolumn{3}{|l|}{ Crashes } \\
\hline & & $\begin{array}{l}\text { Assist (No } \\
\text { Transfer) }\end{array}$ & Assist (Transfer) & Failure to Assist \\
\hline Distributed Advantage & $\begin{array}{l}M=510 \\
P=510\end{array}$ & $M=460, P=500$ & $\begin{array}{l}\mathrm{M}=480 \\
\mathrm{P}=480\end{array}$ & $\begin{array}{l}M=100 \\
P=500\end{array}$ \\
\hline Advantage Value & 1020 & 960 & 960 & 600 \\
\hline $\begin{array}{l}P \text { (Distribution I No } \\
\quad \text { Helmet) }\end{array}$ & 0.7 & 0 & 0.1 & 0.2 \\
\hline Expected Advantage & 714 & 0 & 96 & 120 \\
\hline WEDA & 930 & & & \\
\hline
\end{tabular}

The WEDA value of not wearing a helmet can be similarly represented by the following table (Table 2):

As with Table 1, the distributions represented in this table are defined in terms of the sets of events that generate a particular distribution of advantage. However, this table describes the possible distributions that might arise from the motorcyclist choosing not to wear a helmet. Thus, the numbers in the distributed advantage row have been adjusted to model the distributional consequences of this choice. For example, the motorcyclist is assigned more advantage in Distribution 5 than in Distribution 1, as it is assumed that she derives greater enjoyment from riding without a helmet. Additionally, because WEDA calculations are made under the assumption of full compliance, the motorcyclist is held to transfer half of this surplus advantage to the passerby, thereby leaving both parties with 10 more units of advantage than they are assigned in Distribution 1. Similarly, it is assumed that an accident without a helmet is much more severe than an accident with a helmet. Thus, the motorcyclist is assigned less advantage in Distributions 6, 7, and 8 than in counterpart Distributions 2, 3, and 4. Finally, because the passerby makes an equalizing transfer in Distribution 7 , she ends up with less advantage than she is assigned in counterpart Distribution 3.

Using the procedure described above, these inputs yield a WEDA value of 930 for the choice to not wear a helmet. Given that this value is 40 units less than the WEDA value of wearing a helmet, the proposed theory maintains that the motorcyclist chooses sanctionably when she declines to wear a helmet, and forfeits a claim to 40 units of advantage as a result. Thus, while the passerby is still obliged to assist the motorcyclist after a crash, she is not obligated to make any supplemental transfer to the motorcyclist. This is because mere assistance leaves the motorcyclist 40 units of advantage worse off than the passerby, thereby satisfying the demands of justice. 


\section{Luck egalitarianism without moral tyranny}

The previous two sections have attempted to explain how the proposed theory holds people responsible for destroying ${ }_{\mathrm{FC}}$ advantage such that they cannot leave others with less ${ }_{\mathrm{FC}}$. In other words, these sections have sought to show that the theory satisfies the moral tyranny constraint in a way that strict egalitarianism does not. However, note that this demonstration does not show that the theory fully satisfies the moral tyranny constraint. To fully satisfy the constraint, a theory must not only preclude sanctionable choosers like the motorcyclist from leaving others with less $\mathrm{FC}_{\mathrm{FC}}$ but also preclude those others (e.g., the passerby) from leaving sanctionable choosers with less $\mathrm{FC}_{\mathrm{FC}}$. Only then will it have a theoretical advantage relative to contextualism.

Fortunately, the demonstration of this point is fairly straightforward. Note that contextualism's moral tyranny problem emerges from its claim that the sanctionability of a choice is a function of the actual advantage the chooser foregoes as a result of that choice, where other people are able to affect that latter quantity after the choice has been made-i.e., in a way that makes the loss of advantage unavoidable. Thus, contextualist theories grant people the power to unilaterally render a person's choice sanctionable, thereby stripping the chooser of a claim to advantage, which, in turn, leaves her with less $\mathrm{FC}_{\mathrm{FC}}$. By contrast, the theory proposed here makes sanctionable choice strictly a function of the agent's choice and the evidence already available to her (namely, the evidence about the consequences of various choices under conditions of full compliance). As a result, the agent is able to avoid choosing sanctionably, meaning that others lack the ability to unilaterally leave the agent with less $\mathrm{FC}_{\mathrm{FC}}$. Given that such unilaterality is a necessary condition of moral tyranny, it follows that the proposed theory fully satisfies the moral tyranny constraint in a way that contextualism does not.

Suppose, for example, that the motorcyclist crashes without a helmet and the passerby refuses to assist her. Given that the motorcyclist chose sanctionably by not wearing a helmet, advantage is appropriately distributed just in case the motorcyclist ends up with 40 fewer units of advantage than the passerby. Thus, the passerby who chooses not to provide assistance would also act sanctionably, as the WEDA value of not assisting (600) is lower than the WEDA value of providing assistance without transfer (960). ${ }^{22}$ Thus, according to the proposed theory, the passerby would forfeit a claim to 360 units of advantage, with fully compliant people then transferring that advantage to the motorcyclist. As a result, the motorcyclist would be left with 460 units of advantage rather than 100-i.e., she is not left with less $\mathrm{FC}_{\mathrm{FC}}$ advantage than she would have if the passerby provided assistance. This result demonstrates that the proposed version of luck egalitarianism satisfies the moral tyranny constraint in a way that contextualist luck egalitarianism does not.

\footnotetext{
${ }^{22}$ It is assumed that the probability of each distribution obtaining is 1 conditional on the choice to not assist and assist, respectively. Thus, the WEDA value of each choice is equal to the distributed advantage value of the distribution it will bring about.
} 


\section{Amending the theory}

Before completing the argument, a quick amendment must be made to the theory to avoid an additional objection that might otherwise undermine its plausibility. In its present form, the proposed theory makes sanctionable choice a function of the failure to maximize WEDA assuming full compliance. However, in many cases, people will not comply with the demands of justice. As a result, there will be cases where the choice that maximizes full-compliance WEDA runs contrary to the demands of justice. Consider, for example, David Estlund's Slice and Patch case:

\section{Slice and Patch Go Golfing}

Suppose that unless a patient is cut and stitched he will worsen and die (though not painfully). Surgery and stitching would save his life. If there is surgery without stitching, the death will be agonizing. Ought Slice to do the surgery? This depends, of course, on whether Patch (or someone) will be stitching up the wound. Slice and Patch are each going golfing whether the other attends to the patient or not. Does anyone act wrongly? (2020,33)

In this case, Slice choosing to operate would maximize WEDA under conditions of full compliance, as a fully compliant Patch would stitch up the wound, thereby leaving everyone with maximal equal advantage. However, given that actual Patch will not stitch up the wound, it seems plausible to think that justice demands that Slice refrain from operating (for these purposes, this can simply be stipulated). Given these premises, the posited theory entails a seemingly unacceptable result: Slice declining to operate is both a just choice and a sanctionable choice in virtue of which she forfeits a claim to advantage.

To avoid this problem, the theory can be amended as follows. Rather than define sanctionable choice strictly in terms of a failure to maximize WEDA under conditions of full compliance, a second necessary condition of sanctionable choice can be added to the theory: a person chooses sanctionably if and only if she fails to maximize WEDA under conditions of full compliance and fails to maximize the chances that advantage is appropriately distributed assuming actual compliance. Thus, when Slice chooses not to operate on the patient, she does not choose sanctionably, as the added necessary condition is not met.

Further, the amended theory still satisfies the moral tyranny constraint. Admittedly, when Slice declines to operate, she leaves the patient with less $_{\mathrm{FC}}$ advantage than if she chose to operate. However, recall from Sect. 2 that the moral tyranny constraint is only violated when a theory enables a person to discretionarily leave others with less $_{\mathrm{FC}}$, where a discretionary action is one that is not obligatory according to the theory in question. Given that it is obligatory that Slice not operate, the fact that this choice leaves the patient with less $\mathrm{FC}_{\mathrm{FC}}$ advantage under the proposed theory does not entail that the theory permits moral tyranny. The amended theory thereby avoids declaring just actions sanctionable while also satisfying the moral tyranny constraint. 


\section{Additional advantages of the theory}

In addition to resolving the moral tyranny objection, the proposed theory also solves the two other problems with luck egalitarianism presented in Sect. 1. Recall, first, Arneson's objection that luck egalitarianism delivers incorrect results in cases of costly rescue, e.g., by declaring Mother Teresa to have chosen sanctionably when she gives her money to the poor (Arneson, 2011a, 244; 2011b, 33-34). While this objection seems like a genuine problem for prudential contextualist luck egalitarianism, there are two reasons that the proposed theory would not deliver the result that Mother Teresa chooses sanctionably.

First, there are certain ways of filling in the details of the case such that Mother Teresa maximizes WEDA under conditions of full compliance and, thus, does not choose sanctionably. For example, if the poor are in their position due to bad luck and Mother Teresa has a comparative advantage in transferring advantage, then her actions would be expected to leave others with more FC $_{\text {than }}$ if she focused on generating advantage. Second, even if her actions do not maximize WEDA assuming full compliance, her transfers to the poor would be demanded by a luck egalitarian theory of justice. Thus, her choice to aid the poor does not meet the second necessary condition of sanctionable choice introduced in the previous section. This allows the theory to avoid delivering incorrect results in Arneson's case.

Section 1 also introduced Hurley's "boring problem." Recall that this problem emerges from (a) luck egalitarianism's claim that inequality is justified iff those with less have chosen sanctionably and (b) the standard contextualist view that sanctionable choice is a function of whether or not a person has imprudently failed to maximize her possessed advantage. When taken together, these two claims entail that a comparative relation between levels of advantage can be justified by appealing to a responsibility relation that obtains between a person and her individual holdings. However, Hurley argues that the latter relation does not appear to justify the former: the fact that a person is responsible for having a particular quantity of advantage would not seem to justify others having more advantage, as the person is not responsible for this difference. Thus, Hurley worries that luck egalitarianism is internally incoherent (2003, 160-1).

What is now apparent is that this objection is specific to contextualist versions of luck egalitarianism, as only contextualism maintains that a person's imprudent choices-i.e., those that leave her with some diminished quantity of advantagejustify a comparative inequality in advantage. By contrast, the proposed theory holds a person responsible for failing to position herself and others in a way that would allow everyone to bring about justice without anyone needlessly foregoing advantage. This seems like a much more apt justificans for comparative inequality 
than a person being responsible for her own level of advantage. ${ }^{23}$ Alternatively, the theory suggests that the comparative relation is justified by the fact that this relation obtaining is a necessary condition of avoiding moral tyranny. Regardless of the exact justification offered, the proposed theory solves Hurley's boring problem by explicating why an individual's sanctionable choice justifies inequality despite that individual not being responsible for the inequality in question.

\section{Thaysen and Albertsen and disadvantage creation}

The proposed formulation of luck egalitarianism is similar in certain respects to a revised version of luck egalitarianism proposed by Jens Damgaard Thaysen and Andreas Albertsen (2017). Thus, it is worth explicating their theory in some detail so as to clarify the similarities and differences between the two theories. Specifically, this section will suggest that their theory is best understood as asserting that sanctionable choice is a function of how agents' choices affect the total quantity of advantage. It will then argue that the proposed WEDA-based theory of sanctionable choice has three advantages over this interpretation of Thaysen and Albertsen's account.

Like the proposed account, Thaysen and Albertsen attempt to solve the problem of costly rescues-i.e., the problem illustrated by Arneson's Mother Teresa caseby revising which choices count as sanctionable. Specifically, they posit that a choice is sanctionable iff it creates disadvantage that would not have otherwise been possessed by anyone. For example, if a villain drops a brick off of a building and strikes someone, she creates disadvantage because she leaves someone worse off while no one would have been worse off had she chosen differently (95). By contrast, the hero who pushes someone out of the way of a falling brick and gets struck herself distributes disadvantage, as she merely changes who possesses disadvantage that would have obtained irrespective of her choice (96). In this way, Thaysen and Ablertsen's theory avoids the implication that Mother Teresa makes a

\footnotetext{
23 Gerald Lang (2015) has suggested that the boring problem might be solved by modifying the justificandum of sanctionable choice: rather than have such choice justify a comparative inequality between two persons-i.e., the gap between their respective levels of advantage-it would, instead, justify a gap between an agent's level of advantage and some egalitarian baseline. On this proposal, each person is assigned some baseline share of advantage. If she then ends up with either more or less advantage than her assigned baseline share, that deviation would be just iff the difference between her share and the baseline is attributable to her choices rather than luck $(2015,706)$. The thought here is that, while a person is not responsible for the fact that she has less advantage than someone else, she is responsible for the fact that she ends up with less than her baseline share. Thus, there is no longer a justificatory gap of the kind identified by the boring problem, as the agent's sanctionable choices make her responsible for the state of affairs that those choices are supposed to justify.

However, there are two problems with this proposal. First, as Lang notes, it is unclear how to determine each person's appropriate baseline share (714). Second, note that this proposal still assumes a prudential contextualist theory of sanctionable choice where a choice justifies a deviation from the baseline iff it leaves the agent worse off than she might otherwise have been. Given this assumption, Lang's baseline account is still vulnerable to the moral tyranny objection, making the proposed WEDA account a superior solution to the boring problem.
} 
sanctionable choice when she aids the poor, as she is merely distributing disadvantage to herself rather than creating disadvantage.

To fully explicate Thaysen and Albertsen's proposal, a more precise account of disadvantage creation must be provided. Their formal statement is that an "agent is responsible for creating a (dis)advantage if, and only if, she is responsible for behaving in such a way that somebody was (dis)advantaged" (94). If taken literally, this statement is misleading, as it suggests that an action $\phi$ creates disadvantage iff there is a person who is left worse off in the world where $\phi$ occurs relative to the world where the closest possible world where it does not. ${ }^{24}$ However, this is clearly not how Thaysen and Albertsen intend their analysis to be interpreted, as such an account would entail that the hero creates disadvantage due to the fact that there is a person who is left worse off by her action (namely, herself).

To clarify Thaysen and Andersen's analysis of disadvantage creation, it will be helpful to consider their analysis of disadvantage distribution, as the former is supposed to contrast with the latter. Specifically, they posit that disadvantage distribution occurs iff " $X$, rather than $Y$, was (dis)advantaged" by the agent's action. However, there is some potential ambiguity in this statement that calls for additional precisification. One way of interpreting this analysis is as follows: an agent distributes disadvantage by $\phi$-ing iff $X$ is worse off in the world where the agent $\phi$-s than in the world where she does not $\phi$ and $Y$ is worse off in the latter world than the former. Notably, this restatement delivers the correct results in the hero case, as the hero is worse off in the world where she pushes the beneficiary than the world where she does not push, while the beneficiary is worse off in the latter than in the former. One could then define disadvantage creation as cases where (a) the agent's action leaves someone worse off relative to inaction and (b) the action is not an instance of disadvantage distribution.

The problem with this proposal is that the restated analysis of disadvantage distribution seems to deliver incorrect results. Consider, for example, a modified case where a villain has a small quantity of fun dropping a brick on her victim. In this case, the victim is worse off in the world where the brick is dropped than the world where it isn't; at the same time the villain is worse off in the latter world than in the former (because she has less fun). Thus, the restated account would entail that the villain distributes disadvantage rather than creates it. Given that this is seemingly a paradigmatic case of disadvantage creation, this result is a reductio of the proposed restatement.

So what is a better statement? The apparent solution is to put things in terms of the total quantity of advantage created by an action: an agent distributes disadvantage by $\phi$-ing iff there is the same total quantity of disadvantage in the world where she $\phi$-s as the world where she does not $\phi$. This account seems to deliver the correct results in paradigmatic cases. For example, when the hero saves the beneficiary from the falling brick, the same quantity of disadvantage is generated with only the action merely changing how that disadvantage is

\footnotetext{
${ }^{24}$ This is also the natural way of precisifying Thaysen and Ablertsen's later restatement of duty creation wherein they assert that such creation obtains when "nobody would be worse off if not for [the agent's] exercise of responsibility" (95).
} 
distributed. Thus, the hero merely distributes disadvantage in that case. By contrast, the villain who derives enjoyment from dropping a brick off of a building does not distribute disadvantage, as her action realizes a world with a greater total quantity of disadvantage than the one where she did not act in this way.

One last minor adjustment is needed. The fact that Thaysen and Albertsen use the term "(dis)advantage" when articulating their distribution/creation distinction suggests that they actually take there to be four distinct phenomena: advantage distribution, disadvantage distribution, advantage creation, and disadvantage creation. This fourfold division is incompatible with the just-posited restatement, as it would only allow for disadvantage distribution with there being no apparent acts of advantage creation. To fix this, the analysis could be amended as follows. An agent distributes disadvantage by $\phi$-ing iff (a) there is the same total quantity of disadvantage in the world where she $\phi$-s as there is in the closest possible world where she does not $\phi$ and (b) there is less total advantage after she $\phi$-s than there was just prior to her $\phi$-ing. This joint counterfactual and trans-temporal comparison seems to capture the idea that people are worse off-i.e., there was disadvantage generated-but the agent merely distributes that worsening without contributing to it. The account of advantage distribution would then be identical to the justproposed analysis except that (b) asserts that there is more total advantage after the agent $\phi$-s.

The restatement of (dis)advantage creation is a bit more straightforward, as one can capture the idea of leaving everyone (worse) better off without having to make any trans-temporal comparisons. Specifically, an agent creates disadvantage by $\phi$ ing iff there is less total advantage in the world where she $\phi$-s than in the closest possible world where she does not. And she creates advantage by $\phi$-ing iff there is more total advantage in the world where she $\phi$-s than in the closest possible world where she does not.

This explication helps to reveal the similarities and differences between Thaysen and Albertsen's theory of sanctionable choice and the one posited by this paper. The primary similarity is that both theories reject contextualist theories of sanctionable choice and, instead, make sanctionable choice a function — at least in part-of what effect the agent's choice has on the total quantity of advantage (more on the qualifier below). This allows both theories to sidestep Arneson's objection that luck egalitarianism unacceptably entails that costly rescues are sanctionable. Given that such rescues do not paradigmatically affect the total quantity of advantage, they would not count as sanctionable choices under either theory.

However, there are three important differences that give the posited WEDAbased account a theoretical advantage over Thaysen and Albertsen's proposal. First, their theory makes sanctionable choice strictly a function of created disadvantage rather than the expected advantage value of choices. As a result, their theory entails that the person who makes the choice that maximizes expected advantage but gets unlucky and ends up creating disadvantage chooses sanctionably. For example, suppose a person reasonably believes that there is a probability of 0.9 that she will create 100 units of advantage if she $\phi$-s and a probability of 0.1 that she will create 10 units of disadvantage (i.e., -10 units of advantage). By contrast, if she does not $\phi$, she will create 5 units of disadvantage with a probability of 1 . Given that the 
expected value of $\phi$-ing is 89 while the expected value of not $\phi$-ing is -5 , the agent chooses to $\phi$; however, she gets unlucky and generates 10 units of disadvantage. Given that there is more total advantage in the world where the agent $\phi$-s than the closest possible world where she does not, the posited restatement of Thaysen and Albertsen's proposal entails that she has created disadvantage and can thereby be held responsible - a seemingly unacceptable result. ${ }^{25}$ By contrast, the WEDA account avoids this implication by making sanctionable choice a function of expected total advantage rather than counterfactual advantage comparisons.

A second important difference is that Thaysen and Albertsen's account seemingly declares inequality to be just both when someone chooses sanctionably-i.e., creates disadvantage-and also when she makes a choice that creates advantage. For example, they hold that the miner who happens to strike a vein of gold that no one else would have found creates advantage and is, thus, entitled to keep some of the profits (even if that results in inequality) (98). ${ }^{26}$ However, it seems inappropriate for a luck egalitarian theory to declare such a seemingly luck-based inequality just. After all, the fact that the miner was lucky enough to be uniquely positioned to extract the gold does not seem to justify her ending up better off than everyone else. By contrast, the theory proposed by this paper does not posit such a category of rewardable choice; rather, anything short of maximizing WEDA is sanctionable while maximizing entitles a person to an equal share of advantage relative to the shares of other successful maximizers. Thus, it would not license the proposed inequality.

Finally, while Thaysen and Albertsen make sanctionable choice a function of counterfactual differences in total advantage, the posited account makes sanctionable choice a function of both the quantity and distribution of advantage across possible worlds. This allows the posited WEDA account to avoid seemingly counterintuitive implications of Thaysen and Albertsen's proposal. Consider, for example, a case where $P$ has a choice between realizing world $E$ where she and $Q$ each have 10 units of advantage or world $U$ where she has 5 units of advantage and $Q$ has 20 (assume, for simplicity, that the warranted probability of each outcome is 1). On Thaysen and Albertsen's account-at least, as it has been interpreted here- $P$ would create disadvantage if she realizes $E$, as it has less total advantage than $U$. In other words, if $P$ were to realize the egalitarian distribution, she would thereby make a sanctionable choice for which she could be held responsible. However, this result is seemingly a reductio of any posited theory of luck egalitarianism. By contrast, the theory proposed by this paper would assign a higher

\footnotetext{
25 Thaysen and Albertsen do specify that a choice is sanctionable only if it was foreseeable that it would create disadvantage (100). However, they do not consider cases where the disadvantage creation was foreseeable but not the reasonably expected outcome.

26 Note the caveat that the miner is only entitled to some of the profits. This is because, according to Thaysen and Albertsen, she is only responsible for creating part of the created advantage, as some of that advantage is attributable merely to the resources rather than anything the miner did (98). However, they do not provide an account explicating how one determines the portion of created advantage for which a person is responsible.
} 
WEDA value to $E$, thereby making $P$ 's choice to realize an egalitarian distribution non-sanctionable.

In sum, Thaysen and Albertsen make the right kind of theoretical move by rejecting contextualism in favor of a an account that makes sanctionable choice a function of total advantage. However, their failure to build expected value into their theory, their endorsement of rewardable choice, and their neglect of distributive considerations all lead to their theory delivering unfortunate results. Thus, luck egalitarians troubled by Arneson's objection ought to adopt the proposed WEDAbased theory rather than Thaysen and Albertsen's account.

\section{Conclusion}

This paper has presented an original theory of sanctionable choice that both derives from-and fully satisfies - the theoretical constraint that motivates the adoption of luck egalitarianism. It posited that a choice is sanctionable just in case it fails to maximize warranted expected distributed advantage under conditions of full compliance and fails to maximize the chances that advantage is appropriately distributed assuming actual compliance. It has further argued that defining sanctionable choice in this way allows the theory to ensure that no person is able to unilaterally, discretionarily, and foreseeably leave others with less $\mathrm{FC}_{\mathrm{FC}}$, thereby satisfying the moral tyranny constraint presented above. This result makes the theory superior to both strict egalitarianism and the contextualist versions of luck egalitarianism that dominate the literature. Finally, the paper has argued that the proposed theory also avoids some of the major objections that plague standard interpretations of luck egalitarianism. Thus, the paper claims to have developed a theoretically superior version of luck egalitarianism that might be incorporated into broader debates over distributive justice.

Acknowledgements This project has received funding from the European Research Council (ERC) under the European Union's Horizon 2020 research and innovation programme (grant agreement No 819043). Some of the research incorporated into this paper was also made possible by a generous fellowship provided by the American Council of Learned Societies. I am also indebted to Carol Gould, Peter Vallentyne, Charles Mills, and Miranda Fricker for their comments on an earlier version of this paper, as well as to Chris Fowler for helping me find elegant values for the tables in Sect. 5. Finally, my thanks goes out to the two anonymous referees, as their suggestions did much to help improve this paper.

Funding Open Access funding provided by the IReL Consortium.

Open Access This article is licensed under a Creative Commons Attribution 4.0 International License, which permits use, sharing, adaptation, distribution and reproduction in any medium or format, as long as you give appropriate credit to the original author(s) and the source, provide a link to the Creative Commons licence, and indicate if changes were made. The images or other third party material in this article are included in the article's Creative Commons licence, unless indicated otherwise in a credit line to the material. If material is not included in the article's Creative Commons licence and your intended use is not permitted by statutory regulation or exceeds the permitted use, you will need to obtain permission directly from the copyright holder. To view a copy of this licence, visit http:// creativecommons.org/licenses/by/4.0/. 


\section{References}

Arneson, R. (1989). Equality and equal opportunity for welfare. Philosophical Studies, 56(1), 77-93.

Arneson, R. (2011a). Liberalism, capitalism, and 'socialist' principles. Social Philosophy and Policy, 28(2), 232-261.

Arneson, R. (2011). Luck egalitarianism-a primer. In C. Knight \& Z. Stemplowska (Eds.), Responsibility and distributive justice.Oxford University Press.

Cohen, G. A. (2006). Luck and equality: A reply to Hurley. Philosophy and Phenomenological Research, 72(2), 439-446.

Cohen, G. A. (2008). Why not socialism? Princeton University Press.

Cohen, G. A. (2009). Rescuing justice and equality. Harvard University Press.

Cohen, G. A. (2011). On the currency of egalitarian justice. In M. Otsuka (Ed.), On the currency of egalitarian justice and other essays in political philosophy.Princeton University Press.

Dworkin, R. (1981). What is equality? Part 2: Equality of resources. Philosophy and Public Affairs, 10, 283-345.

Dworkin, R. (2000). Sovereign virtue: The theory and practice of equality. Harvard University Press.

Estlund, D. (2020). Utopophobia. Princeton University Press.

Fleurbaey, M. (1995). Equal opportunity or equal social outcome? Economics and Philosophy, 11(1), 25-55.

Hurley, S. (2003). Justice, luck, and knowledge. Harvard University Press.

Jeffers, M. T. (2020). Luck and the limits of equality. Philosophical Papers, 49(3), 397-429.

Knight, C. (2013). Egalitarian justice and expected value. Ethical Theory and Moral Practice, 16(5), 1061-1073.

Knight, C., \& Stemplowska, Z. (2011). Introduction. In C. Knight \& Z. Stemplowska (Eds.), Responsibility and distributive justice.Oxford University Press.

Kymlicka, W. (2002). Contemporary political philosophy (2nd ed.). Oxford University Press.

Lang, G. (2015). How interesting is the 'boring problem' for luck egalitarianism? Philosophy and Phenomenological Research, 91(3), 698-722.

Lippert-Rasmussen, K. (2015). Luck egalitarianism. Bloomsbury Publishing.

McKerlie, D. (1989). Equality and time. Ethics, 99(3), 475-491.

Olsaretti, S. (2009). Responsibility and the consequences of choice. Proceedings of the Aristotelian Society, 109(2), 165-188.

Otsuka, M. (2010). Justice as fairness: Luck egalitarian, not rawlsian. The Journal of Ethics, 14(3-4), 217-230.

Scanlon, T. M. (1998). What we owe each other. Bellknap Press.

Segall, S. (2010). Health, luck, and justice. Princeton University Press.

Segall, S. (2013). Equality and opportunity. Oxford University Press.

Segall, S. (2016). Why inequality matters: Luck egalitarianism, its meaning and value. Cambridge University Press.

Stemplowska, Z. (2009). Making justice sensitive to responsibility. Political Studies, 57, 237-259.

Stemplowska, Z. (2013). Rescuing luck egalitarianism. Journal of Social Philosophy, 44(4), 402-419.

Temkin, L. (1993). Inequality. Oxford University Press.

Temkin, L. (2011). Justice, equality, fairness, desert, rights, free will, responsibility, and luck. In C. Knight \& Z. Stemplowska (Eds.), Responsibility and distributive justice.Oxford University Press.

Thaysen, J. D., \& Albertsen, A. (2017). When bad things happen to good people: Luck egalitarianism and costly rescues. Politics, Philosophy \& Economics, 16(1), 93-112.

Vallentyne, P. (2002). Brute luck, option luck, and equality of initial opportunities. Ethics, 112(3), 529-557.

Vallentyne, P. (2008). Brute luck and responsibility. Politics, Philosophy \& Economics, 7(1), 57-80.

Publisher's Note Springer Nature remains neutral with regard to jurisdictional claims in published maps and institutional affiliations. 